\title{
CONF-980104--
}

\section{Systematic Approach for \\ PID Controller Design for \\ Pitch-Regulated, \\ Variable-Speed Wind Turbines}

AECEUED

NoV 241997

M. Maureen Hand

Mark J. Balas

Presented at

ASME $17^{\text {th }}$ Wind Energy Symposium

Reno, Nevada

January 12-15, 1998

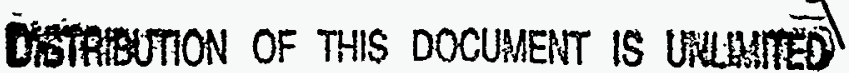
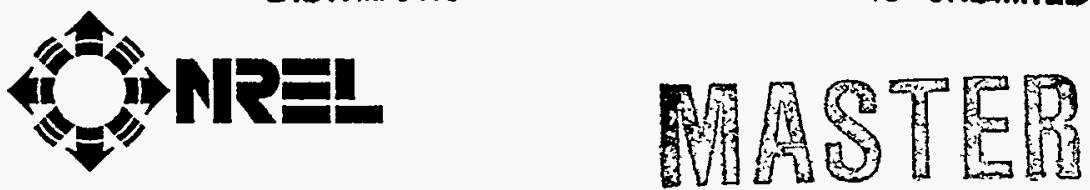

National Renewable Energy Laboratory 1617 Cole Boulevard Golden, Colorado 80401-3393

A national laboratory of the U.S. Department of Energy Managed by Midwest Research Institute for the U.S. Department of Energy under contract No. DE-AC36-83CH10093

Work performed under task number WE801110

November 1997 


\section{NOTICE}

This report was prepared as an account of work sponsored by an agency of the United States govemment. Neither the United States govemment nor any agency thereof, nor any of their employees, makes any warranty, express or implied, or assumes any legal liability or responsibility for the accuracy, completeness, or usefulness of any information, apparatus, product, or process disclosed, or represents that its use would not infringe privately owned rights. Reference herein to any specific commercial product, process, or service by trade name, trademark, manufacturer, or otherwise does not necessarily constitute or imply its endorsement, recommendation, or favoring by the United States govemment or any agency thereof. The views and opinions of authors expressed herein do not necessarily state or reflect those of the United States government or any agency thereof.

Available to DOE and DOE contractors from:

Office of Scientific and Technical Information (OSTI)

P.O. Box 62

Oak Ridge, TN 37831

Prices available by calling (423) $576-8401$

Available to the public from:

National Technical Information Service (NTIS)

U.S. Department of Commerce

5285 Port Royal Road

Springtield, VA 22161

(703) $487-4650$ 


\section{DISCLAIMER}

Portions of this document may be illegible electronic image products. Images are produced from the best available original document. 


\title{
SYSTEMATIC APPROACH FOR PID CONTROLLER DESIGN FOR PITCH- REGULATED, VARIABLE-SPEED WIND TURBINES ${ }^{*}$
}

\author{
M. Maureen Hand \\ National Wind Technology Center, National Renewable Energy Laboratory \\ 1617 Cole Blvd, Golden, CO 80401-3393 \\ Tel: (303)384-6933; email: maureen_hand@nrel.gov \\ Mark J. Balas \\ Department of Aerospace Engineering Sciences \\ University of Colorado at Boulder, $\mathrm{CO}$ 80309-7881 \\ Tel: (303)492-3177; email: mark.balas@colorado.edu
}

\begin{abstract}
Variable-speed, horizontal axis wind turbines use blade-pitch control to meet specified objectives for three regions of operation. This paper focuses on controller design for the constant power production regime. A simple, rigid non-linear turbine model was used to systematically perform trade-off studies between two performance metrics. Minimization of both the deviation of the rotor speed from the desired speed and the motion of the actuator is desired. The robust nature of the proportional-integral-derivative (PID) controller is illustrated, and optimal operating conditions are determined. Because numerous simulation runs may be completed in a short time, the relationship of the two opposing metrics is easily visualized.
\end{abstract}

\section{INTRODUCTION}

Because variable-speed wind turbines have the potential for increased energy capture, controller design has become an area of increasing interest. Blade-pitch regulation provides means for initiating rotation, varying rotational speed to extract power at low wind speeds, and maintaining power production at a maximum level. Controllers must be designed to meet each of these objectives, and this study pertains only to constant power production, or Region 3 operation.

The Region 3 regime is entered when the turbine reaches the design rotor speed for maximum power production. Under these conditions, rotational speed is constrained to a specified maximum value through blade-pitch regulation. Fluctuations in wind speed are accommodated to prevent large excursions from the desired rotational speed. Thus the power production is also constrained to a relatively constant level. In addition to maintaining a constant rotational speed, actuator movement must be restrained to prevent fatigue and overheating. The combination of maintaining a constant rotational speed and minimizing actuator motion are the control objectives specified for Region 3 operation.

\section{DYNAMIC MODELNG}

A simple, rigid, non-linear turbine model was developed for the purpose of controller design ${ }^{1}$ The geometry and aerodynamic characteristics of the simulated turbine resemble those of a Grumman Windstream 33, 10-m diameter, 20-kW turbine. The National Renewable Energy Laboratory's National Wind Technology Center modified this turbine to operate at variable-speeds using blade-pitch regulation. The fundamental dynamics of a variable-speed wind turbine are captured with the following simple mathematical model:

$$
J_{T} \dot{\omega}_{T}=Q_{A}-Q_{E}
$$

The moment of inertia of the turbine rotor is represented by $J_{T} ; \omega_{T}$ is the angular shaft speed; $Q_{E}$ is the mechanical torque necessary to turn the generator and was assumed to be a constant value commanded by the generator. Because the generator moment of inertia is generally several

- This paper is declared a work of the U.S. Government and is not subject to copyright protection in the United States. 
orders of magnitude less than $J_{\mathrm{T}}$, it has been neglected. The aerodynamic torque, $Q_{A}$ is represented by:

$$
Q_{A}=\frac{1}{2} \rho A R c_{q}(\lambda, \beta) w^{2} .
$$

The air density, $\rho$, swept area of the rotor, A, and rotor radius, $R$, are constant. The wind speed is given by $w$. The torque coefficient, $c_{q}$, is a function of tip-speed ratio, $\lambda$, and blade-pitch angle, $\beta$. The tip-speed ratio is the ratio of the blade tip speed to the prevailing wind speed. The non-linear aerodynamic characteristics are implemented as a look-up table which was generated using PROPPC. ${ }^{2}$ This aerodynamics code uses blade-element momentum theory and empirical models that predict stalled operation and blade tip losses.

The block diagram in Figure 1 illustrates the simulation logic. Actual wind data sampled at 1 $\mathrm{Hz}$ is input to the non-linear plant model. The turbine speed is fed back, and the reference speed, $\omega_{I} \mathrm{OP}$, is subtracted from it resulting in $\Delta \omega_{\mathrm{T}}$ (noise in the sensor measurements has been neglected). This rotor-speed error is input to the controller, shown in Figure 2, which commands a change in blade-pitch angle, $\Delta \beta$, based on $\Delta \omega_{T}$. The new pitch angle requested is then $\beta=\Delta \beta+\beta_{o p}$, which is physically limited to angles between 3 and $60 \mathrm{deg}$. The actuator, pictured in Figure 3, operates on a pitch-rate command which is limited to \pm 10 $\mathrm{deg} / \mathrm{second}$ to reduce actuator fatigue. Constant motion of the actuator increases the temperature of the motor which may damage it In addition to potential thermal overload, constant actuator motion reduces the fatigue life of the linkage in the actuator system. The pitch rate is determined from the difference between the commanded pitch angle and the measured blade-pitch angle (noise in the measurements is again neglected). Another measure meant to reduce actuator motion and eliminate noise in the command signal (once it is introduced in the simulation) is the inclusion of a "dead zone" to ignore commanded pitch rates less than $\pm 0.1 \mathrm{deg} / \mathrm{second}$. The simulation uses a variable step size with a maximum of 0.05 seconds. A new wind speed is read from the input file when the simulation time step corresponds to the time step of the wind data. A new rotational speed is then determined at the resulting tip-speed ratio and blade-pitch angle.
In order to assess controller performance, two metrics were developed.' The root mean square (RMS) of the error between the actual rotational speed and the desired rotational speed indicates the capability of the controller to reject the wind speed fluctuations. After the simulation is completed $(100 \mathrm{~s})$, the RMS of the error is computed. The Actuator Duty Cycle (ADC) was proposed as a measure of actuator motion during a simulation run. It is simply the total number of degrees pitched over the time period of the simulation. For each simulation run, these two metrics were computed, and both must be considered in determining acceptable operating conditions.

\section{TRADITIONAL CONTROLLER DESIGN METHODOLOGY}

A traditional approach to design of commonly used linear controllers such as proportional-integralderivative (PID), requires that the nonlinear turbine dynamics be linearized about a specified operating point. This results in the following equation assuming that $\mathrm{Q}_{\mathrm{A}} \mathrm{OP}_{\mathrm{O}}=\mathrm{Q}_{\mathrm{E}} \mathrm{OP}_{\mathrm{OP}}$ :

$$
J_{T} \dot{\omega}_{T}=\gamma \Delta \omega_{T}+\alpha \Delta w+\delta \Delta \beta,
$$

where the linearization coefficients are given by

$$
\begin{aligned}
& \gamma=\left.J_{T} \frac{\partial \dot{\omega}_{T}}{\partial \omega_{T}}\right|_{O P}=\left.\frac{1}{2} \rho A R^{2} w_{O P} \frac{\partial c_{q}}{\partial \lambda}\right|_{O P} \\
& \alpha=\left.J_{T} \frac{\partial \dot{\omega}_{T}}{\partial w}\right|_{O P}=\frac{1}{2} \rho A R w_{O P}\left[\left.2 c_{q}\right|_{O P}-\left.\lambda_{O P} \frac{\partial c_{q}}{\partial \lambda}\right|_{O P}\right] \\
& \delta=\left.J_{T} \frac{\partial \dot{\omega}_{T}}{\partial \beta}\right|_{O P}=\left.\frac{1}{2} \rho A R w_{O P}{ }^{2} \frac{\partial c_{q}}{\partial \beta}\right|_{O P} .
\end{aligned}
$$

Here, $\Delta \omega_{\mathrm{T}}, \Delta \mathrm{w}$, and $\Delta \beta$ represent deviations from the chosen operating point, $\omega_{\mathrm{T}} \mathrm{OP}, \omega_{\mathrm{OP}}$, and $\beta_{\mathrm{OP}}$. The operating point was chosen to insure stable operating conditions. ${ }^{1}$ Using the following parameters: $R=5 \mathrm{~m}, J_{\mathrm{T}}=1270 \mathrm{~kg} / \mathrm{m}^{2}$, $w_{O P}=7.5 \mathrm{~m} / \mathrm{s}$, $\omega_{\mathrm{T} O P}=11 \mathrm{rad} / \mathrm{s}$, and $\beta_{O P}=9$ degrees, the values for the linearization coefficients were: $\alpha=300 \mathrm{~N} \cdot \mathrm{s}$, $\delta=-150 \mathrm{~N} \cdot \mathrm{m} / \mathrm{deg}$, and $\gamma=-150 \mathrm{~N} \cdot \mathrm{m} \cdot \mathrm{s}$.

The closed-loop transfer function between the output rotational speed and the reference speed is determined in the Laplace domain. The denominator of this equation is a second order 
polynomial. Because it is second order, a Routh array analysis requires each of the coefficients of the polynomial to be positive in order for the poles of the system to lie in the left-half plane indicating stable operation. The gains must be as follows in order to maintain stability: $\mathrm{k}_{\mathrm{p}}>1 \mathrm{deg} \cdot \mathrm{s} / \mathrm{rad}, \mathrm{k}_{\mathrm{f}}>0$ $\mathrm{deg} / \mathrm{rad}$, and $\mathrm{k}_{\mathrm{D}}>8 \mathrm{deg} \cdot \mathrm{s}^{2} / \mathrm{rad}$. For this linear approximation of the system, stability is maintained over a wide region.

At this point the designer may examine the system response to step input in order to select values for each of the gains. A step function approximates an abrupt change in wind speed and was used to tune the PI controller. ${ }^{1}$ Visual inspection of response functions for the two metrics, RMS speed error and actuator duty cycle, may be used to determine the best combination of $\mathrm{k}_{\mathrm{P}}$ and $\mathrm{k}_{\mathrm{I}}$ gains to achieve appropriate damping of the system. However, when the third gain is introduced, this trial and error method becomes much more tedious and complicated. This method does not provide the designer with a feel for the sensitivity of the controller to slight variations in the gain values, and an optimal range of gain values is not identified.

\section{SYSTEMATIC CONTROLLER DESIGN METHODOLOGY}

In order to systematically determine combinations of three gains that produce acceptable operating conditions, the simulation was used repeatedly. Each of the gains was varied from 1 to 75 , and the two metrics were computed for each run. Additionally, five different wind input cases were used. The average value of the metrics under each combination of gains was computed. Contour plots for both metrics were created while the $k_{p}$ and $k_{D}$ were varied at a specific $\mathrm{k}_{\mathrm{f}}$. This was done for a range of $\mathrm{k}_{\mathrm{I}}$ values from 1 to 75 . Figures 4-6 depict surfaces for three different values of $k_{I}$ for both of the metrics. Trade-off studies between the series of surfaces were performed to determine regions where optimal operating conditions exist. Lastly, time-series traces of rotational speed, pitch angle, and pitch rate for gain combinations within this region were produced to verify acceptable operation.

\section{RESULTS}

All of the contour plots, Figures 4-6, indicate wide, flat surfaces for both the actuator duty cycle and the RMS of the rotational speed error. These surfaces indicate that a wide range of gain value combinations may be chosen with similar results. Thus the controller is robust and relatively insensitive to changes in the values of the gains. However, choosing optimal operating setpoints for the gains requires closer examination of the surfaces.

The actuator duty cycle surface for $k_{\Gamma}=1$, Figure $4 a$, indicates that the mean value decreases rapidly to zero as $k_{P}$ and $k_{D}$ approach one. Figure $5 a$, which represents the surface at $k_{\Gamma}=5$, portrays the opposite effect near $k_{P}=1$ and $k_{D}=1$, but a "bucket" with a minimum value of $0.9-1.0$ appears at moderate gain values of 5-15 for both $k_{P}$ and $k_{D}$. As the value of $k_{I}$ is further increased to 10 in Figure $6 a$, the "bucket" again appears, but its minimum value of 1.0-1.1 is greater than that of the "bucket" that appears at $k_{\mathrm{r}}=5$. Therefore, the minimum value of actuator duty cycle over the entire range of the three gain values occurs somewhere between $k_{I}=1$ and $\mathrm{k}_{\mathrm{i}}=5$.

A similar comparison of the RMS speed error surfaces was performed to determine the location of its minimum value over the entire range of gain values. Figure $4 \mathrm{~b}$ indicates a sharply increasing slope in the RMS speed error for $k_{\mathrm{p}}<25$. As the integral gain, $\mathrm{k}_{\mathrm{f}}$, increases from 1 to 5 in Figure $5 \mathrm{~b}$, this sharp slope boundary decreases to $k_{\mathrm{P}}<14$. Increasing the integral gain to 10 , Figure $6 b$, moves the slope increase to $k_{\mathrm{P}}<10$. The RMS speed error slowly decreases as $\mathrm{k}_{\mathrm{p}}$ increases such that the minimum value would occur beyond the range of the plot. However, for all three values of $k_{I}$, the surface flattens to a mean RMS speed error of 0.10.15. Thus changing the value of $\mathrm{k}_{\mathrm{I}}$ alters the increasing slope as the proportional gain is reduced, but the flat region from which the sloped area originates is maintained.

Both the RMS speed error and the actuator duty cycle must be considered in choosing the optimal operating conditions. If the integral gain were reduced from a value of 5 , the RMS speed error surface would retain similar characteristics, but the boundary of increasing slope would begin to increase from $k_{\mathrm{P}}=10$. The actuator duty cycle surface would also retain similar characteristics, but the sharp rise as $k_{p}$ and $k_{D}$ approach one would begin to drop toward zero. The "bucket" would remain in approximately the same location. Thus, reducing $\mathrm{k}_{\mathrm{I}}$ from 5 has little effect on the actuator duty cycle in the region of the "bucket," but the corresponding RMS speed error in that region increases. However, if the integral gain were 
increased, the "bucket" would begin to rise. Therefore, in order to minimize the RMS speed error and the actuator duty cycle simultaneously, the integral gain should be set at 5 .

Using an integral gain of 5 , the minimum actuator duty cycle region corresponds to an RMS speed error range of $0.25-0.3$. The point $A$ on Figure $5 a$ and $5 b$ represents operating conditions where the actuator duty cycle is minimized $\left(\mathrm{k}_{\mathrm{p}}=8, \mathrm{k}_{\mathrm{F}}=5\right.$, $k_{D}=12$ ). An example of operation in the highest actuator duty cycle range uses the operating condition at Point $B\left(\mathrm{k}_{\mathrm{P}}=65, \mathrm{k}_{\mathrm{T}}=5, \mathrm{k}_{\mathrm{D}}=60\right)$ shown on Figure $5 \mathrm{a}$ and $5 \mathrm{~b}$. Because the RMS speed error slowly decreases as the proportional and derivative gains are increased, this point also indicates operation in the low end of the lowest RMS speed error range. To determine which metric is more important, time-series traces of one simulation are presented in Figures 7 and 8 for Point A and Point $B$ respectively. The wind speed in this case represents the highest average wind speed used in this study which produces the most extreme conditions.

Figures 7 and 8 show time-series traces of rotational speed, pitch angle, and pitch rate over a 100 second period. The first 10 seconds exhibit the initial transient from the established operating point and should be neglected. Operation at Point A, shown in Figure 7, represents the trade-off between minimum actuator duty cycle and a higher level of RMS speed error. The rotational speed deviation from the desired 105 RPM is slightly greater than \pm 5 RPM. The pitch rate does not exceed $\pm 5 \mathrm{deg} / \mathrm{s}$. In this case the goal of maintaining constant rotational speed is not met satisfactorily. Operation at Point $B$, shown in Figure 8, depicts the trade-off between minimum RMS speed error and a higher level of actuator duty cycle. In this case the rotational speed deviation from the reference is less than \pm 2 RPM, and the pitch rate reaches the limit of $10 \mathrm{deg} / \mathrm{s}$. The pitch rate also indicates excessive motion at approximately $\mathbf{5 5}$ seconds. This type of motion is unacceptable when attempting to reduce fatigue and the potential for overheating.

Point $C\left(k_{P}=30, k_{1}=5, k_{D}=20\right)$ was chosen at the intersection of the minimum RMS speed error range and the lowest corresponding actuator duty cycle. The rotational speed, pitch angle, and pitch rate obtained at this operating point are shown in Figure 9. The rotational speed closely tracks the desired 105 RPM throughout the simulation with peak deviations of less than \pm 3 RPM. The actuator duty cycle does not reach the limit, and the curve is smoother than that of Figure 8. Operation within this region results in the best possible combination of the two performance metrics.

\section{CONCLUSIONS}

This systematic approach to controller design provides a means of visually observing the effect of gain changes on both RMS speed error and actuator duty cycle. While these metrics are opposing by nature, the surfaces permit selection of gain values that produce favorable results for both of the metrics. The simplicity of the model requires minimal computation time such that hundreds of simulations can be completed within a few hours. The resolution of the contour plots may easily be improved by increasing the number of simulations. This visualization of the effect of gains indicates that the controller is robust over a wide range of gains.

Although the controller is robust, several considerations must be made. First of all, the simulation is extremely simplified from actual turbine operation, and noise has not been incorporated in the simulation. Small differences between simulations will be exacerbated by more complicated dynamics and sensor noise when these gains are implemented in the field. However, it is hoped that the choice of operating conditions using the simulation will also be satisfactory for the field turbine. The effect of changing the operating point in the simulation has not been studied thus far, and the robust characteristics may not be evident at other operating points. Lastly, this systematic approach still requires judgement on the part of the designer. A mathematical relationship between the two metrics could eliminate this requirement if such can be found.

\section{REFERENCES}

'Kendall, L.; Balas, M.J.; Lee, Y.J.; Fingersh, L.J. (1997). "Application of Proportional-Integral and Disturbance Accommodating Control to Variablespeed Variable Pitch Horizontal Axis Wind Turbines." Wind Engineering (12:1); pp. 21-38.

${ }^{2}$ Tangler, J.L. (1987). User's Guide. A Horizontal Axis Wind Turbine Performance Prediction Code for Personal Computers. Golden, CO: Solar Energy Research Institute. 


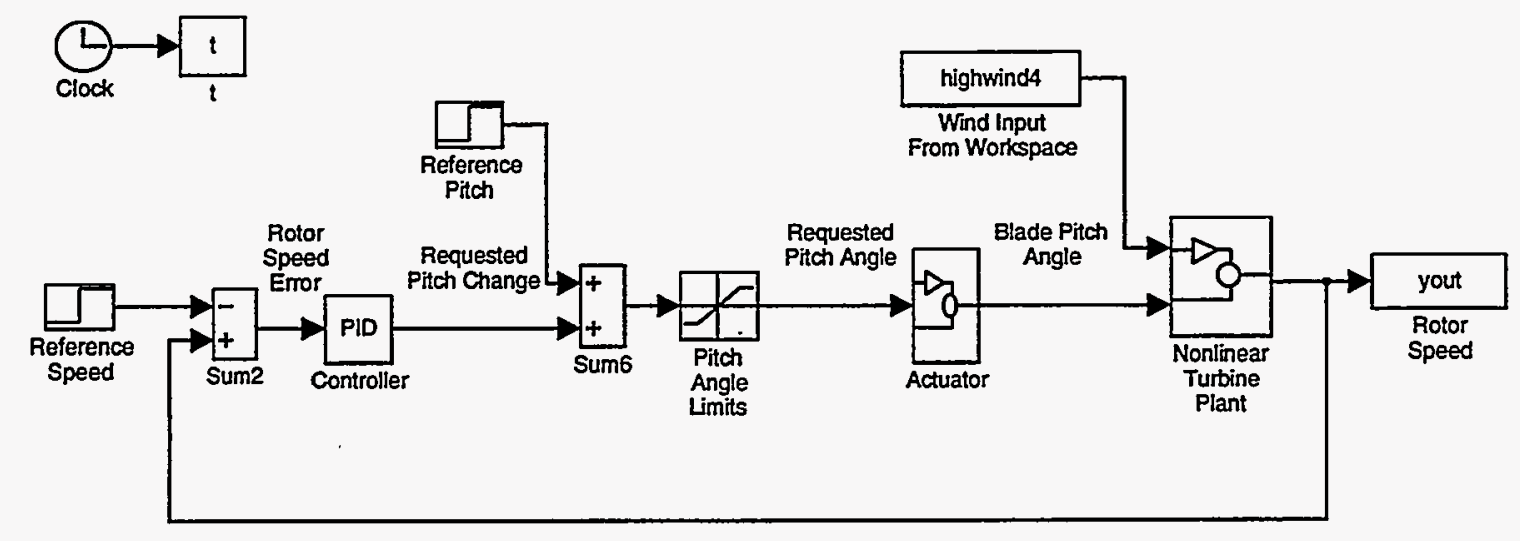

Figure 1. Block diagram of turbine control simulation.

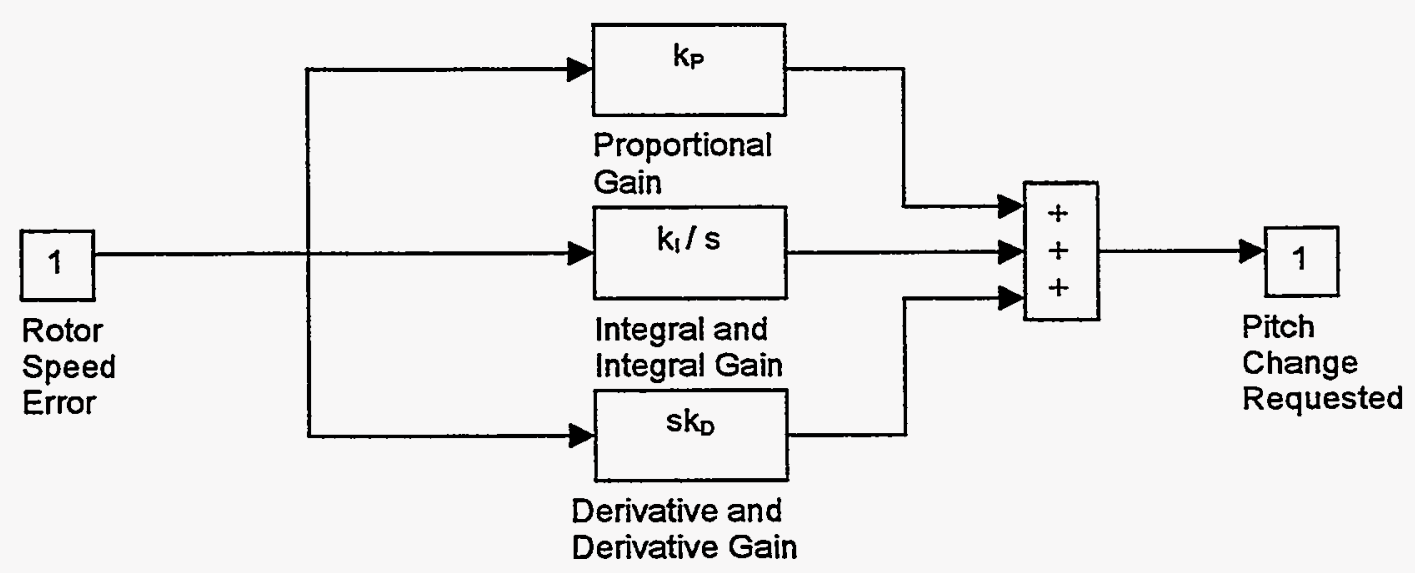

Figure 2. Proportional-Integral-Derivative controller block diagram.

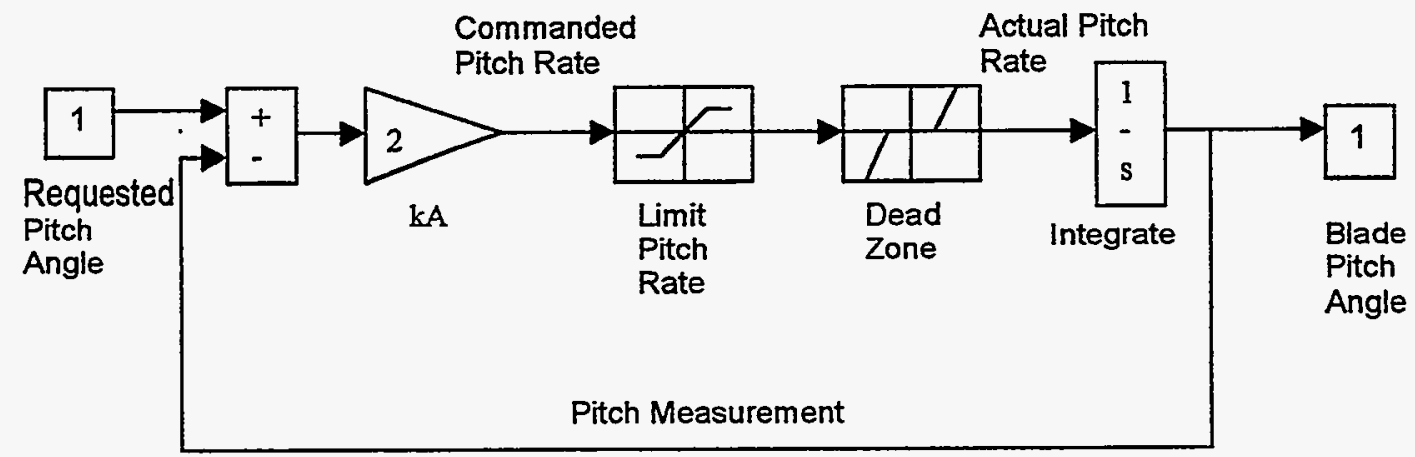

Figure 3. Actuator block diagram. 


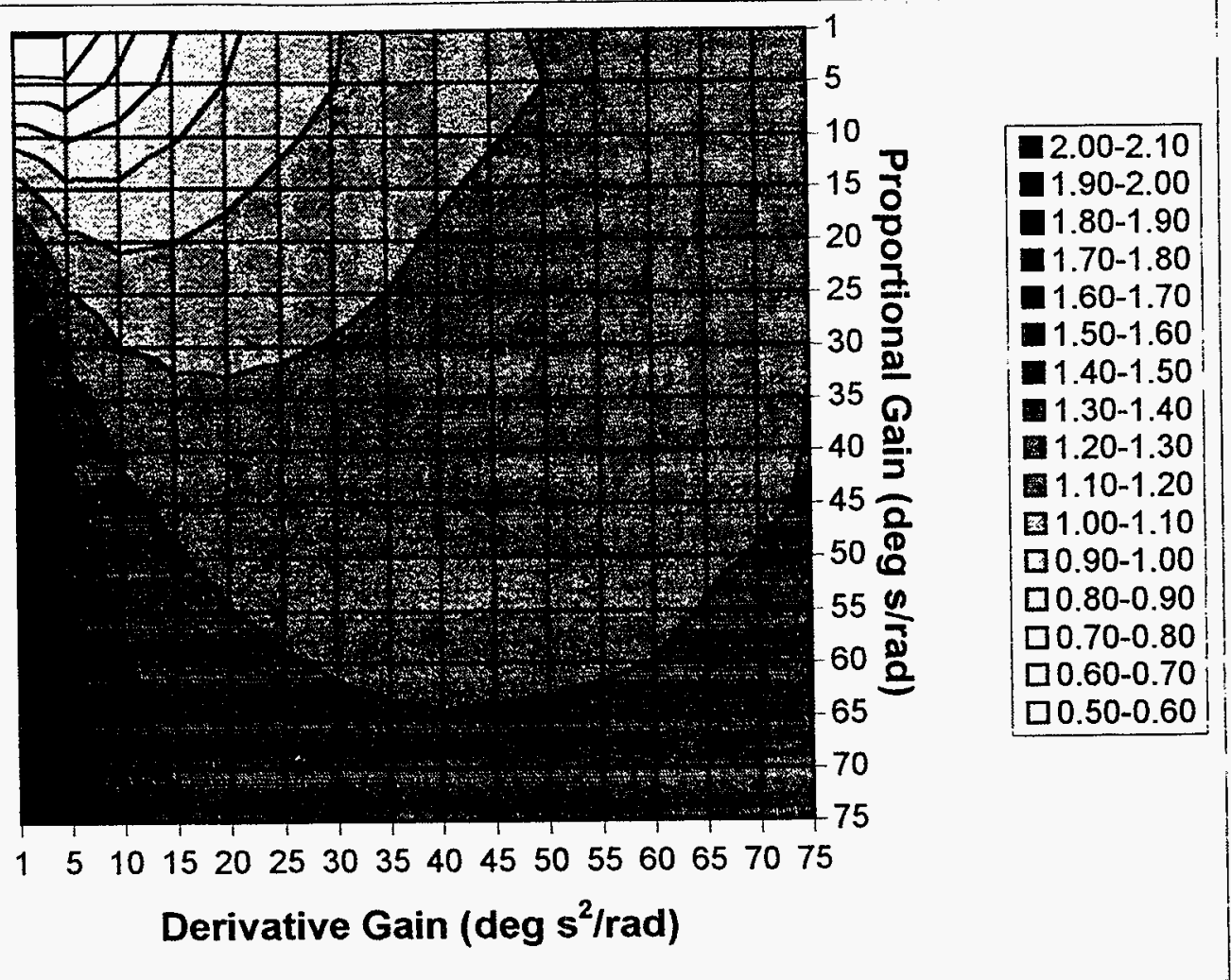

Figure 4(a). Mean actuator duty cycle (deg/second) for $k_{\Gamma}=1$ deg/rad.

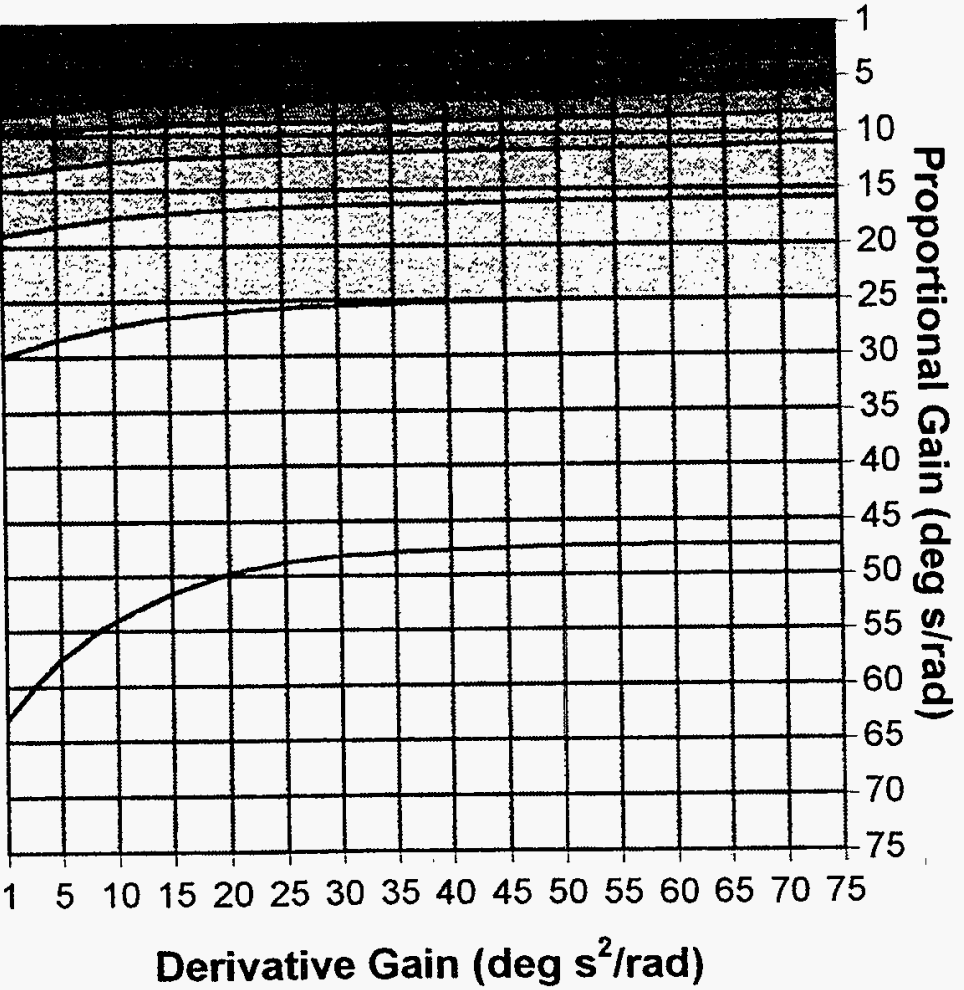

$0.45-0.50$

0.40-0.45

‥35-0.40

0.30-0.35

圆 $0.25-0.30$

口0.20-0.25

口0.15-0.20

口0.10-0.15

$\square 0.05-0.10$

$\square 0.00-0.05$

Figure 4(b). Mean RMS speed error ( $\mathrm{rad} / \mathrm{second}$ ) for $\mathrm{k}_{\mathrm{\Gamma}}=\mathrm{l} \mathrm{deg} / \mathrm{rad}$. 


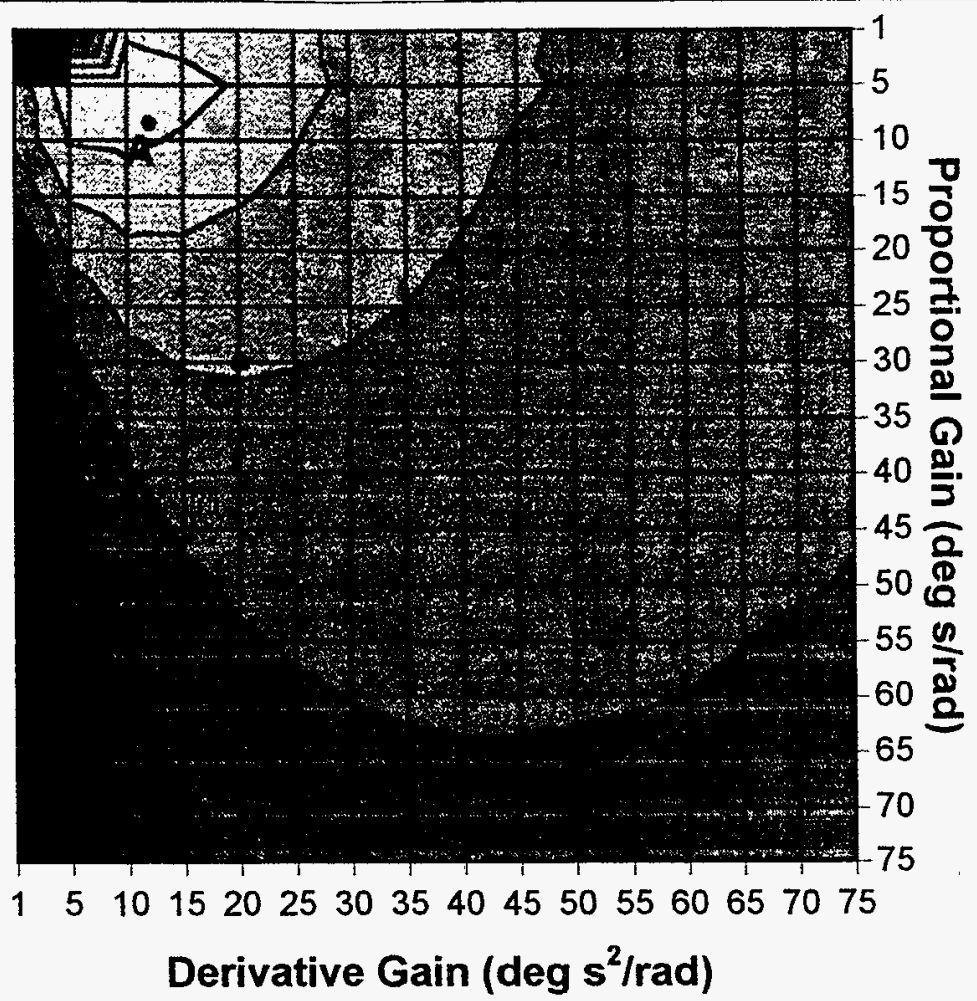

2.00-2.10

=1.90-2.00

- 1.80-1.90

$11.70-1.80$

- 1.60-1.70

-1.50-1.60

1.40-1.50

1.30-1.40

1.20-1.30

国 1.10-1.20

D1.00-1.10

0.90-1.00

口0.80-0.90

$\square 0.70-0.80$

口0.60-0.70

$\square 0.50-0.60$

Figure 5(a). Mean actuator duty cycle (deg/second) for $\mathrm{k}_{\bar{\Gamma}}=5 \mathrm{deg} / \mathrm{rad}$.

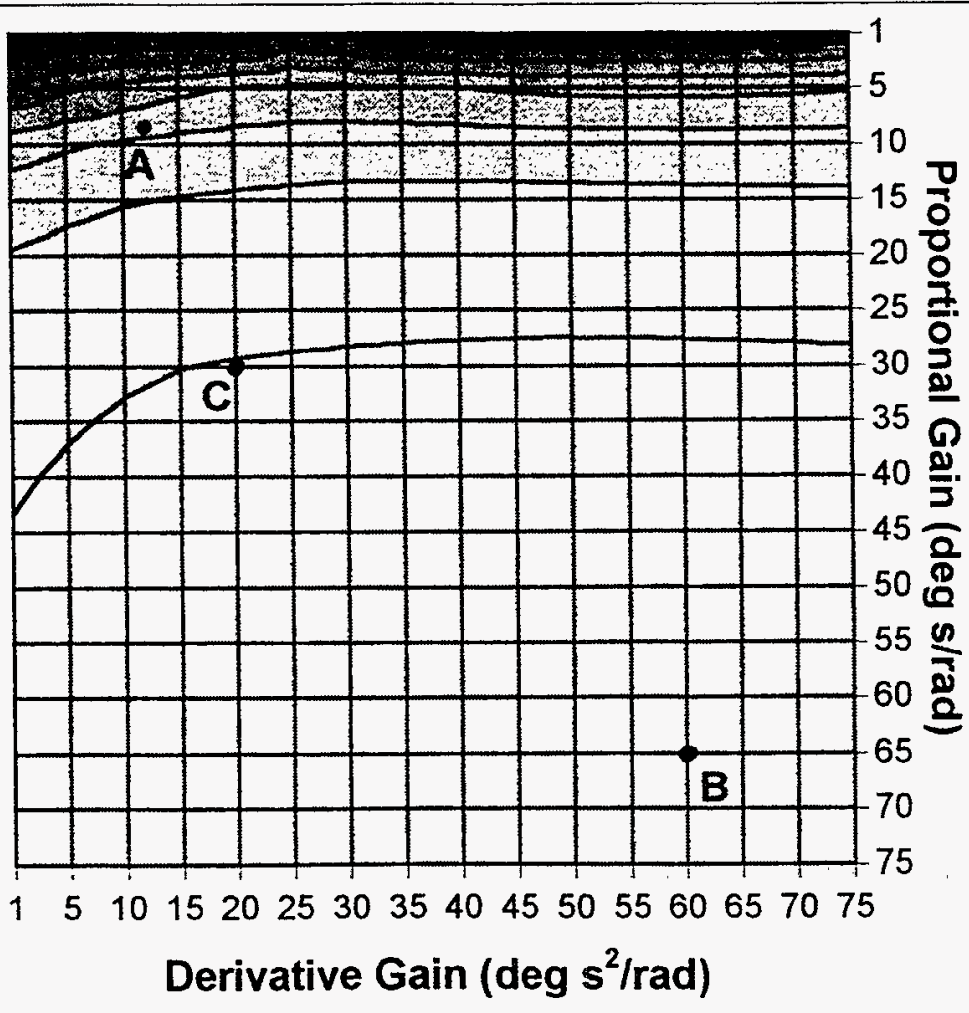

$0.45-0.50$

$0.40-0.45$

0.35-0.40

0.30-0.35

ए0.25-0.30

$\square 0.20-0.25$

ㅁ.15-0.20

ㅁ.10-0.15

ㅁ.05-0.10

口0.00-0.05

Figure 5(b). Mean RMS speed error (rad/second) for $\mathrm{k}_{\mathrm{i}}=5 \mathrm{deg} / \mathrm{rad}$. 


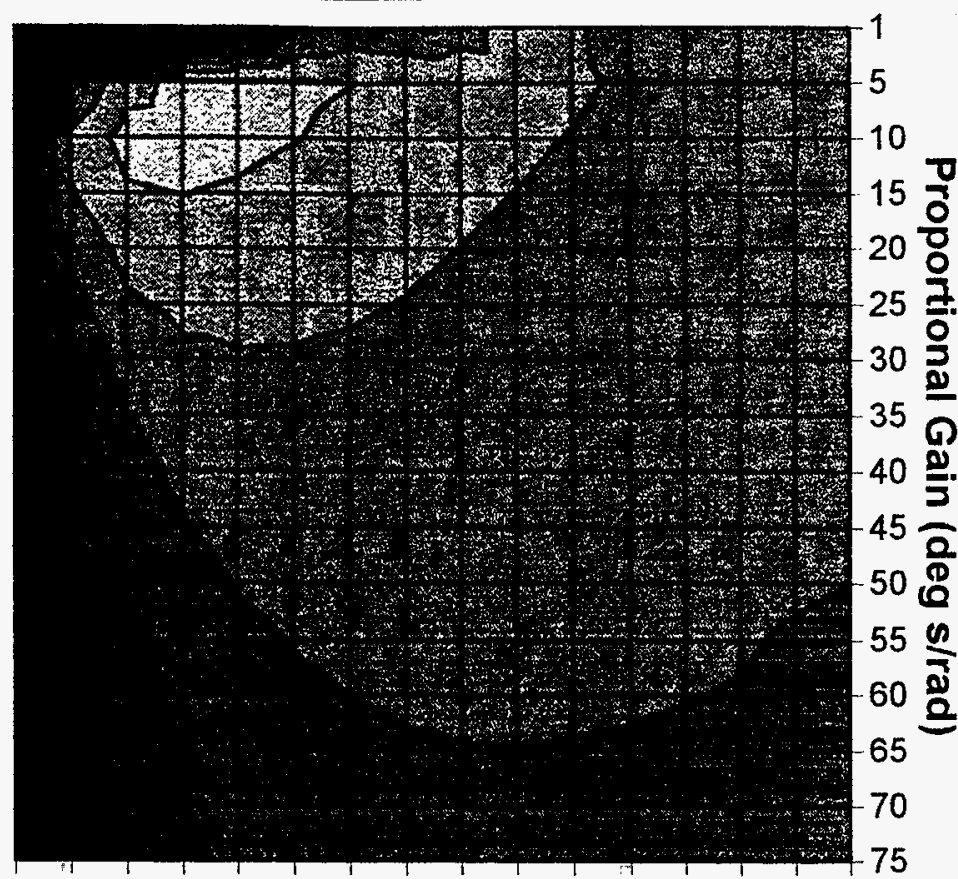

Derivative Gain (deg $\mathbf{s}^{2} / \mathrm{rad}$ )

Figure 6(a). Mean actuator duty cycle (deg/second) for $k_{\Gamma}=10 \mathrm{deg} / \mathrm{rad}$.

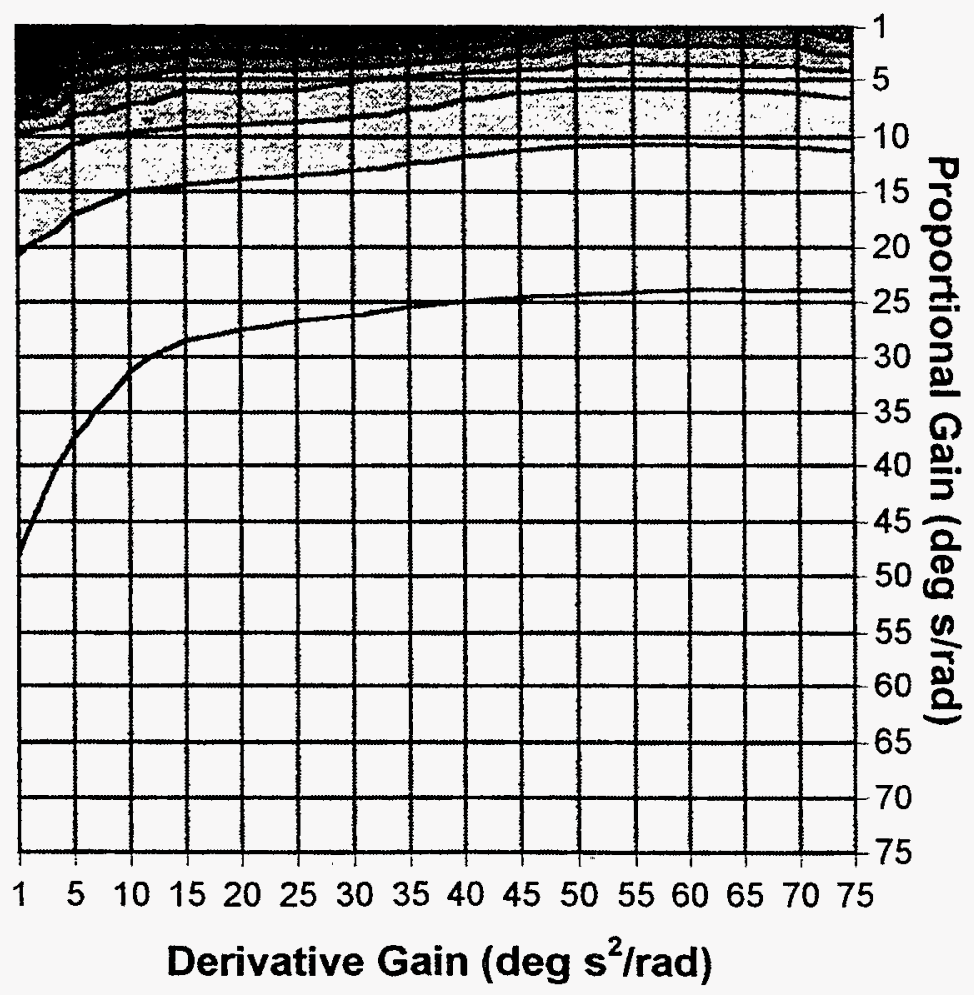



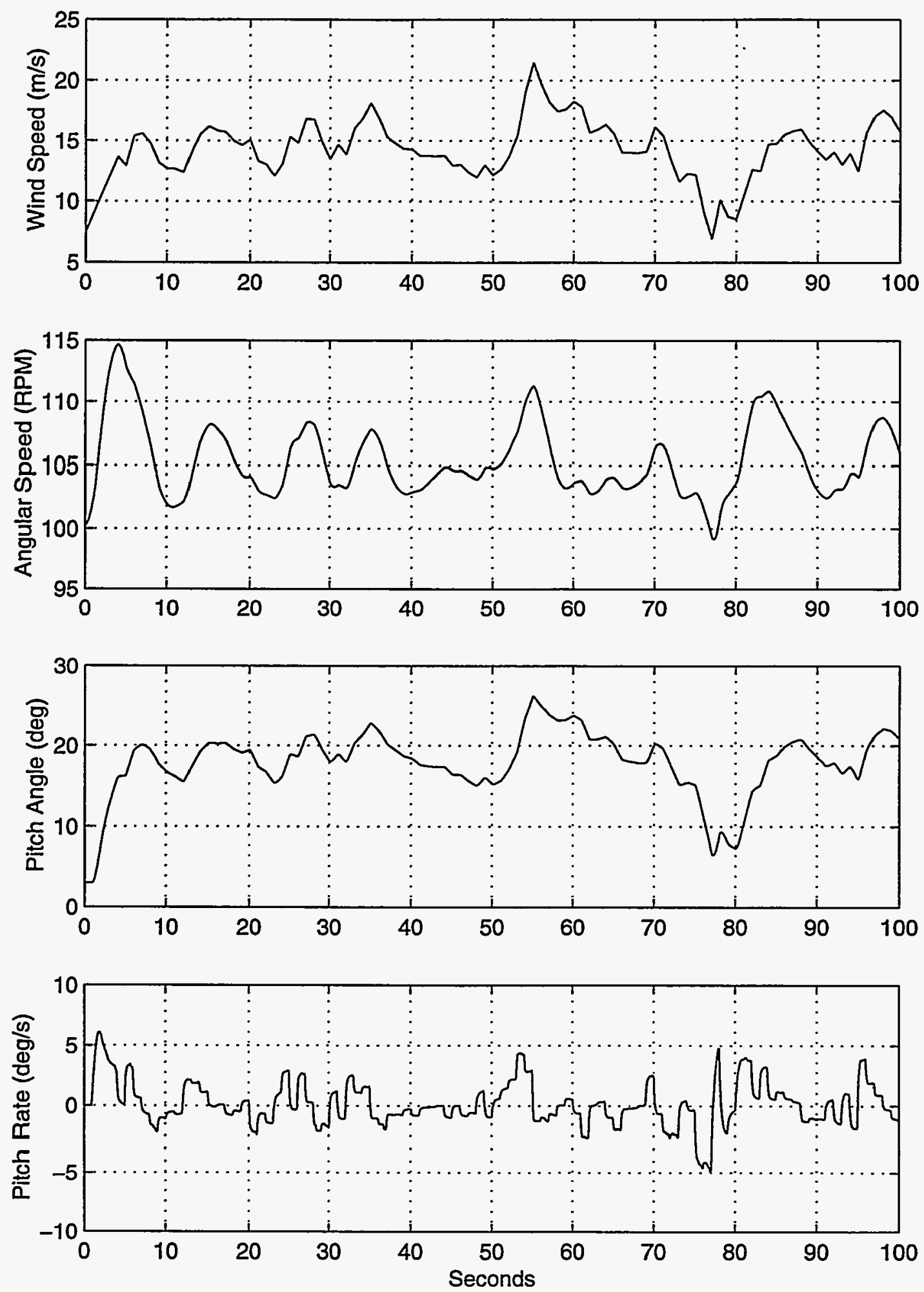

Figure 7. Simulation using the high wind speed input with $\mathrm{k}_{\mathrm{P}}=8 \mathrm{deg} \cdot \mathrm{s} / \mathrm{rad}, \mathrm{k}_{\mathrm{I}}=5 \mathrm{deg} / \mathrm{rad}$, and $\mathrm{k}_{\mathrm{D}}=12$ $\mathrm{deg} \cdot \mathrm{s}^{2} / \mathrm{rad}$. This corresponds to Point $\mathrm{A}$ in Figure 5. 

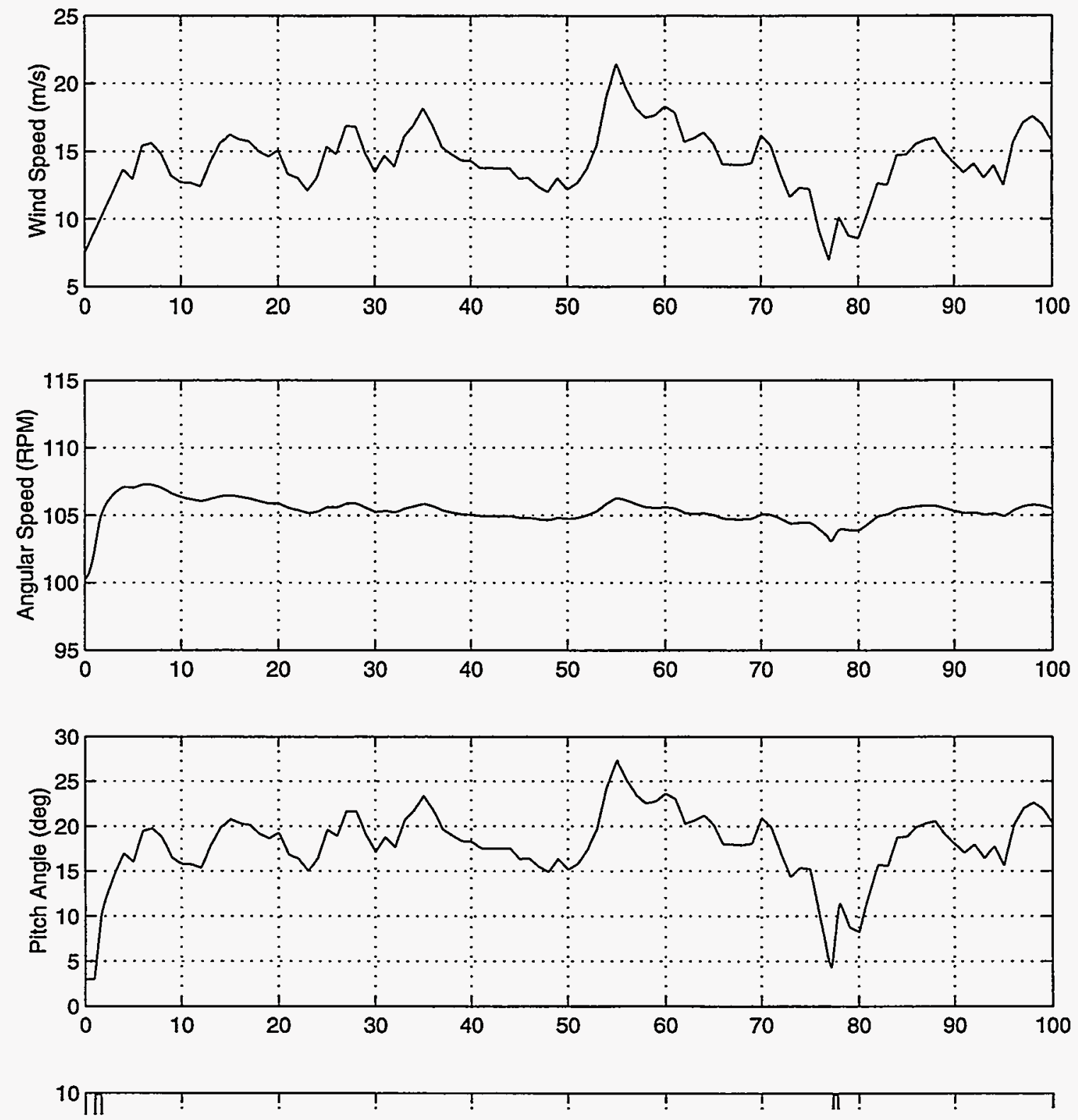